\title{
Effect of Wirestem Severity on Survival and Head Production of Transplanted Broccoli and Cabbage
}

\author{
Anthony P. Keinath, Associate Professor, Clemson University, Department of Plant Pathology and Physiology, \\ Coastal Research and Education Center, Charleston, SC 29414; and Mark W. Farnham, Research Geneticist, \\ USDA-ARS, United States Vegetable Laboratory, Charleston, SC 29414
}

\begin{abstract}
Keinath, A. P., and Farnham, M. W. 2001. Effect of wirestem severity on survival and head production of transplanted broccoli and cabbage. Plant Dis. 85:639-643.

Field experiments were conducted with transplants of Brassica oleracea with known severity levels of wirestem caused by Rhizoctonia solani anastomosis group 4. Seedlings of broccoli and cabbage were grown in steamed soil infested with $R$. solani at 5 to 25 sclerotia $/ \mathrm{kg}$. Two weeks after inoculation, plants were separated into five severity classes based on wirestem symptoms, then transplanted into fumigated field plots in the spring and fall of 1995. The percentage of plants with and without aboveground symptoms was assessed at 14 and 42 days after transplanting. Marketable-sized heads were harvested eight times. In both seasons, percentages of symptomless plants, surviving (symptomless plus symptomatic) plants, and plants producing a marketable-sized head decreased as wirestem severity increased. Only 33 and $29 \%$ of cabbage transplants with $>75 \%$ of the stem circumference girdled survived and produced a marketable head, respectively, compared with 95 and $83 \%$ of healthy transplants, respectively. For broccoli, only $15 \%$ of transplants with girdled stems survived and produced heads in spring but, in the fall, 74 and $72 \%$ of transplants with girdled stems survived and produced heads, respectively. Percentage of plants producing a marketable-sized head was highly correlated $(P=0.0001)$ with percentage of symptomless plants at 14 days after transplanting and percentage of surviving plants at 42 days after transplanting.
\end{abstract}

Rhizoctonia solani Kühn is the main soilborne fungal pathogen causing pre- and post-emergence damping-off of cole crops (Brassica oleracea L.) that reduces the number of plants per hectare $(5,14)$. Surviving plants may be stunted due to wirestem, a disease characterized by dark lesions of varying depth and length on the hypocotyl at or just above the soil line $(4,5,8,9)$. Wirestem reduces the number and weight of marketable-sized heads of cabbage $(5,11,12)$. In the southeastern United States, anastomosis group (AG) 4 is the most prevalent and damaging AG of $R$. solani that attacks Brassica spp., although AG 2-1 also causes wirestem $(1,10)$.

Wirestem incidence and severity on cole crop seedlings are highly correlated with a decrease in seedling plant weight $(9,10)$. In on-farm trials in the 1920s, Gratz (5) found that setting cabbage transplants "slightly" and "severely" affected with wirestem reduced marketable head weight by 10 and

Corresponding author: A. P. Keinath

E-mail: tknth@clemson.edu

Technical contribution 4639 of the South Carolina Agriculture and Forestry Research System, Clemson University, Clemson.

Accepted for publication 27 February 2001.

Publication no. D-2001-0410-01R

(C) 2001 The American Phytopathological Society
$30 \%$, respectively. Other heading types of $B$. oleracea, such as broccoli, may respond similarly. The relationship between wirestem severity on transplants and subsequent yield loss has not been examined in detail or quantified since that early study.

In addition to reducing yield, wirestem may delay maturity of heading $B$. oleracea crops. Gratz (5) estimated that using "slightly diseased" cabbage transplants delayed harvest by 7 to 10 days. Delayed maturity may change the net return on the crop because of seasonal fluctuations in market prices and the costs of additional pesticide applications and additional labor for multiple harvests (16).

The objectives of this study were to determine the relationship between transplant disease severity and plant survival, yield, and days to harvest for broccoli and cabbage. In order to create and quantify distinct severity levels of wirestem, plants were inoculated in the greenhouse before transplanting to the field.

\section{MATERIALS AND METHODS}

Production of diseased transplants. $R$. solani AG-4 isolate SP1 was obtained from a diseased spinach root in Bamberg County, South Carolina, in December 1991 (8) and stored on soil-wheat bran at $-20^{\circ} \mathrm{C}$ (2). Sclerotia were produced on autoclaved green beans and sieved to collect those 710 to $1,000 \mu \mathrm{m}$ in diameter (15), which were stored at $-4^{\circ} \mathrm{C}$ for 1 to 4 months before use. Germination of sclerotia older than 1 month was tested before each experiment by placing 100 sclerotia on water agar and counting the number that germinated after 1 and 2 days.

Seed of broccoli (B. oleracea L., Italica Group, 'Packman') and cabbage (B. oleracea L., Capitata Group, 'Bravo') were sown in commercial potting mix (Metromix 360, Grace Sierra, Milpitas, CA) in 150 -cell trays in a greenhouse. Two weeks later (on 27 March and 8 September 1995), 500 seedlings of each crop were transplanted into 72-cell trays. Hypocotyls were covered to the cotyledons with steamed sandy loam soil infested with $R$. solani sclerotia. In the spring, cabbage was inoculated with $R$. solani at 5 sclerotia $/ \mathrm{kg}$ of soil and broccoli was inoculated with $R$. solani at $5,12.5$, and 25 sclerotia $/ \mathrm{kg}$ of soil. A lower inoculum level was used with cabbage because Bravo cabbage is more susceptible to wirestem than Packman broccoli (9). In the fall, both crops were inoculated with $R$. solani at 25 sclerotia/ $\mathrm{kg}$ of soil to increase the number of severely diseased transplants.

Two weeks after inoculation, plants at the four- to five-leaf stage were removed from the trays and gently washed with a stream of water to remove soil adhering to roots. Plants were sorted into five wirestem severity classes that were used as treatments in the field. The five severity classes were derived from a previously published rating scale (9) based on wirestem symptoms on the stems and overall growth. The severity classes were: healthy = no symptoms of wirestem at transplanting; superficial stem necrosis $=$ longitudinal cracks $\geq 1$ $\mathrm{cm}$ long and marginal discoloration along the crack; stem partially girdled $=\leq 75 \%$ of the stem circumference girdled $\geq 1 \mathrm{~mm}$ deep; stem girdled $=>75$ to $100 \%$ of the stem circumference girdled; and stem completely girdled and plant stunted. Plants missing lateral roots or a taproot due to root rot were not used. Immediately after sorting, roots of plants were immersed in water, one container per severity class and crop, and taken to the field for transplanting.

Field experiments. Field plots were established at the Coastal Research and Education Center, Charleston, SC, in a Dupont very fine sandy loam soil (an Aquult), $\mathrm{pH}$ 6.6. For both experiments, soil was disced twice, after which raised beds were shaped, 
fumigated by injecting $98 \%$ methyl bromide- $2 \%$ chloropicrin $15 \mathrm{~cm}$ deep at 121 $\mathrm{kg} / \mathrm{ha}$, and covered with black polyethylene mulch for $\geq 2$ weeks to reduce levels of indigenous $R$. solani. Before planting, mulch was removed and $15 \mathrm{~N}-0 \mathrm{P}-12.5 \mathrm{~K}$ commercial fertilizer was applied at 730 $\mathrm{kg} / \mathrm{ha}$.

The experimental design was a split plot with four replications. The whole plot treatment was crop (broccoli or cabbage) and the five subplot treatments were wirestem severity classes. Whole plots were single raised beds, $0.9 \mathrm{~m}$ wide, spaced $1.8 \mathrm{~m}$ apart. Whole plot treatments were separated by $1.5 \mathrm{~m}$ within beds. Subplots were arranged linearly within the whole plot beds. Each subplot was $0.9 \mathrm{~m}$ wide and $1.5 \mathrm{~m}$ long, with two rows of plants spaced $30 \mathrm{~cm}$ apart. Transplants were spaced $15 \mathrm{~cm}$ apart within rows; stems were covered with soil up to the cotyledons. Transplants were set on 10 April and 22 September 1995. Twenty transplants were set per subplot, except when not enough transplants were available in the more severe wirestem classes. In the spring, treatments with partially girdled stems, girdled stems, and stunted plants had 7, 9, and 10 cabbage transplants and 5, 7, and 6 broccoli transplants per subplot, respectively. In the fall, treatments with partially girdled stems, girdled stems, and stunted plants had 17, 13, and 19

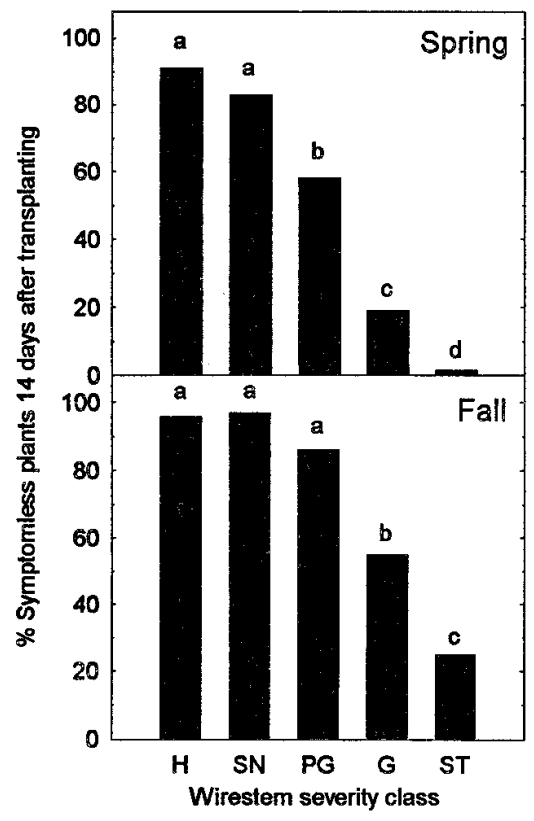

Fig. 1. Mean percentage of symptomless cabbage and broccoli plants 14 days after transplanting seedlings with different severity levels of wirestem. Wirestem severity classes, determined prior to transplanting, were healthy $(\mathrm{H})$, superficial stem necrosis (SN), partially girdled stem (PG), girdled stem $(\mathrm{G})$, and stunted seedling (ST). Means within season with the same letter do not differ by least-squares means $t$ tests, $P \leq 0.001$. There were no significant differences between crops. cabbage transplants and 19, 6, and 5 broccoli transplants per subplot, respectively.

Insects, primarily foliar-feeding caterpillars, were managed with weekly applications of Bacillus thuringiensis at 0.6 to 1.2 $\mathrm{kg}$ a.i./ha. Additional insecticides applied included $\lambda$-cyhalothin at $0.03 \mathrm{~kg}$ a.i./ha on 5 and 9 May, esfenvalerate at $0.06 \mathrm{~kg}$ a.i./ha on 18 May and 3 October, and permethrin at $0.1 \mathrm{~kg}$ a.i./ha on 26 October. Plants were side-dressed with $33.5 \mathrm{~N}-0 \mathrm{P}-$ $0 \mathrm{~K}$ fertilizer at $280 \mathrm{~kg} / \mathrm{ha}$ on 11 May and 16 November. Chlorothalonil was applied at $1.26 \mathrm{~kg}$ a.i./ha on 2 June to prevent Alternaria leaf spot.

Based on our previous field study, transplants were rated for disease severity 2 weeks after transplanting, when wirestem development generally reaches an upper limit (9). In addition, a second rating was made at 6 weeks after transplanting to assess any change in the number of surviving plants. Plants were rated as symptomless, symptomatic, or dead based on visual symptoms. Plants were considered symptomatic if a purplish-black, sunken lesion was visible on the hypocotyl at the soil line or if leaves were bluish-green and wilted and the plant was stunted $(3,8)$. Plants were considered dead when all leaves had senesced. The numbers of symptomless and symptomatic plants were summed to calculate the number of surviving (living) plants. Marketable-sized heads (10-cm diameter for broccoli and $15-\mathrm{cm}$ diameter for cabbage) were harvested and counted eight times between 24 May and 30 June 1995 (approximately every 5 days) and 16 November 1995 and 3 January 1996 (approximately every 7 days). Heads were not weighed, based on previous research that showed no effect of wirestem on mean head weight $(11,12)$.

Statistical analysis. Analysis of variance was performed with PROC GLM of SAS (release 6.12; SAS Institute, Inc., Cary, NC). All data sets were tested for equality of variance and normality before analysis, but transformations usually were not necessary. Different numbers of transplants were used in the different treatments; therefore, analyses of variance were weighted by the inverse of the number of transplants originally planted (13); and $t$ tests on least-squares means, which adjust for different sample sizes, were used to compare treatment means and interactions of crop and treatment (SAS Institute, Inc.). The mean number of days from transplanting to harvest for each plot was calculated by multiplying the number of heads harvested on each harvest date by the days after planting for that date, then dividing this product by the total number of heads harvested.

\section{RESULTS}

Disease. The percentage of plants without aboveground symptoms 14 days after transplanting generally decreased as wire- stem severity on transplants increased, although more plants with any stem girdling (the three most severe wirestem classes) exhibited symptoms in the spring than in the fall (Fig. 1). In both seasons, transplants that were girdled or stunted had significantly fewer symptomless plants than the healthy control, but transplants with only superficial stem necrosis did not differ significantly from the healthy control. At 14 days after transplanting, the percentage of symptomless plants did not differ significantly between crops and there was no crop-treatment interaction. A small number $(<10 \%)$ of plants in the healthy control plots exhibited symptoms of wirestem, likely due to infection after transplanting by residual indigenous $R$. solani in the soil.

In the spring, at 14 days after transplanting, percent survival of cabbage plants with any stem girdling was significantly lower than for healthy control plants or plants with superficial stem necrosis (Table 1). However, only stunted broccoli transplants had lower survival than the healthy control (crop-treatment $F$-test significant at $P \leq 0.002$ ). At 42 days after transplanting, percent survival for both crops was significantly lower for plants with any stem girdling than for healthy plants or plants with superficial stem necrosis (Table 1). In addition, percent survival was lower for girdled or stunted transplants than for transplants that had only partially girdled stems. Percent survival of cabbage was significantly lower at 42 than at 14 days after planting only for transplants with girdled stems $(P=0.002$; Table 1$)$. For broccoli, however, survival was significantly reduced over time for the three most severe wirestem classes $(P=0.0001)$.

The overall percentage of surviving plants generally was higher in the fall than in the spring (Table 1). At 14 days after transplanting, only stunted transplants had lower survival than the healthy control for both crops. At 42 days after transplanting, all but three of the surviving cabbage and broccoli plants had no aboveground visible symptoms $(0.6 \%$ symptomatic of 470 plants examined). As in the spring, percent survival for both crops at 42 days after transplanting in the fall was significantly lower for girdled and stunted transplants than for healthy plants or plants with superficial stem necrosis (Table 1). Percent survival for both crops was significantly lower at 42 than at 14 days after planting for the two treatments with girdled or stunted transplants $(P \leq 0.003)$. The only significant difference between crops was for girdled transplants at 42 days after transplanting, where fewer cabbage than broccoli plants survived $(P \leq 0.0001)$.

Yield. For cabbage and broccoli in the spring and for cabbage in the fall, plants in the healthy control treatment formed the greatest number of marketable-sized heads, $10-\mathrm{cm}$ diameter for broccoli and $15-\mathrm{cm}$ 
diameter for cabbage (data not shown). For broccoli in the fall, the highest yield occurred on plants with superficial stem necrosis. However, in both experiments with both crops, the percentage of plants forming a marketable head in the treatment with superficial stem necrosis did not differ from the healthy controls (Table 2).

In the spring, both cabbage and broccoli plants with any stem girdling (the three most severe wirestem classes) produced significantly fewer heads than the healthy control (Table 2). Seedlings that were stunted at transplanting did not survive and there was no yield ( $100 \%$ loss) in this treatment. In the fall, cabbage plants that had girdled stems or were stunted produced fewer marketable heads than plants in the other three severity classes. However, only broccoli plants that were stunted at transplanting yielded less than the healthy control. In the fall, fewer cabbage plants with girdled stems produced a marketable head $(29 \%)$ than did broccoli plants with the same degree of wirestem $(72 \% ; P=$ 0.0001 ), which was the only yield difference between the two crops.

The percentage of surviving plants that produced marketable heads did not differ among wirestem severity classes or crops in either season. In spring, 81 to $89 \%$ of the broccoli and 76 to $92 \%$ of the cabbage plants (range across wirestem severity classes) that survived at least 42 days after transplanting produced heads. In the fall, 60 to $87 \%$ and 89 to $92 \%$ of the cabbage and broccoli survivors, respectively, produced heads. Averaged across crops and seasons, $89 \%$ of the healthy control plants produced marketable heads.

In the spring, approximately $90 \%$ of the broccoli and cabbage heads reached marketable size $(10-\mathrm{cm}$ diameter for broccoli and $15-\mathrm{cm}$ diameter for cabbage) in the first and second halves of the harvest period, respectively. Likewise, in the fall, $77 \%$ of the cabbage reached marketable size in the second half of the harvest period, but broccoli plants produced marketable-sized heads over the entire harvest period. In general, mean days required to produce a marketable-sized head did not differ greatly between the healthy control and transplants with wirestem. In the spring, cabbage with partially girdled stems produced marketable-sized heads an average of 67.5 days after transplanting, significantly faster than the 75.2 days after transplanting for the healthy control $(P=$ $0.01)$. Broccoli plants with girdled stems reached marketable size 49.0 days after transplanting, faster than the 56.9 days for transplants with partially girdled stems $(P$ $=0.001$ ), but neither treatment differed from the healthy control, with a mean of 54.9 days after transplanting. In the fall, broccoli transplants that were partially girdled, girdled, and stunted took 87.6, 84.1, and 85.5 days after transplanting, respectively, to produce marketable heads, compared with 78.0 days for the healthy control $(P \leq 0.01,0.04$, and 0.01 , respectively). Days to produce a marketable head did not differ among treatments for cabbage in the fall (range of 96 to 100 days after transplanting).

Correlations. The percentage of symptomless plants 14 days after transplanting was highly correlated with percentage of surviving plants 42 days after transplanting and with percentage of plants producing a marketable head $(P=0.0001$; Table 3$)$. Percentage of surviving plants at 42 days after transplanting also was highly correlated with the percentage of plants producing a marketable head. The regression of mean percentage of plants heading on mean percentage of symptomless plants 14 days after transplanting (Fig. 2) and the regression of mean number of marketablesized heads harvested per plot on mean number of symptomless plants 14 days after transplanting were highly significant (regression $F$ significant at $P=0.0001$ ). Slopes for the two regressions were identical $\left(y=0.15+0.86 x, R^{2}=0.96\right.$ and $y=$ $0.01+0.86 x, R^{2}=0.99$, respectively, where $y=$ percentage and number of plants producing marketable heads and $x=$ percentage and number of symptomless plants). Neither season nor cultivar influenced the slope or intercept of the predicted regression line.

\section{DISCUSSION}

By determining the level of wirestem on B. oleracea transplants before setting them in the field, we were able to quantify the longterm survival and yield of the same plants. Broccoli and cabbage transplants that had more severe wirestem symptoms on stems when they were set in the field exhibited aboveground symptoms more frequently and did not survive as long as did healthy or less severely diseased transplants. In both seasons and for both crops, the percentage of plants that showed no aboveground symptoms 14 days after transplanting and the percentage of plants that survived 6 weeks after transplanting decreased with increasing wirestem severity determined immediately before trans-

Table 2. Percentage of cabbage and broccoli transplants with different levels of wirestem severity producing marketable-sized heads in spring and fall experiments ${ }^{\mathrm{x}}$

\begin{tabular}{lccccc}
\hline & \multicolumn{2}{c}{ Spring } & & \multicolumn{2}{c}{ Fall $^{\mathbf{y}}$} \\
\cline { 2 - 3 } \cline { 5 - 6 } Wirestem severity class $^{\mathbf{z}}$ & Cabbage & Broccoli & & Cabbage & Broccoli \\
\hline Healthy & $83.8 \mathrm{a}$ & $77.5 \mathrm{a}$ & & $82.5 \mathrm{a}$ & $81.3 \mathrm{ab}$ \\
Superficial stem necrosis & $71.3 \mathrm{a}$ & $75.0 \mathrm{a}$ & & $72.5 \mathrm{a}$ & $92.5 \mathrm{a}$ \\
Stem partially girdled & $43.8 \mathrm{~b}$ & $40.0 \mathrm{~b}$ & & $65.6 \mathrm{a}$ & $80.3 \mathrm{ab}$ \\
Stem girdled & $29.8 \mathrm{~b}$ & $15.2 \mathrm{c}$ & & $29.4 \mathrm{~b}$ & $71.6 \mathrm{~b}$ \\
Plant stunted & $0.0 \mathrm{c}$ & $0.0 \mathrm{c}$ & & $14.4 \mathrm{~b}$ & $30.0 \mathrm{c}$ \\
\hline
\end{tabular}

x Percentage of plants originally set in the field producing a marketable-sized head (10-cm diameter for broccoli and $15-\mathrm{cm}$ diameter for cabbage). Means within the same column with the same letter do not differ according to least-squares means $t$ tests, $P \leq 0.05$.

${ }^{y}$ Crop-treatment interaction, $F$ significant at $P=0.05$.

${ }^{\mathrm{z}}$ Immediately before transplanting, seedlings were separated into wirestem severity classes based on symptoms on stems.

Table 1. Percentage of cabbage and broccoli transplants with different levels of wirestem severity that survived at 14 and 42 days after transplanting in spring and fall experiments ${ }^{\mathrm{x}}$

\begin{tabular}{|c|c|c|c|c|c|c|c|c|}
\hline \multirow[b]{3}{*}{ Wirestem severity class ${ }^{y}$} & \multicolumn{4}{|c|}{ Spring } & \multicolumn{4}{|c|}{ Fall } \\
\hline & \multicolumn{2}{|c|}{ Cabbage } & \multicolumn{2}{|c|}{ Broccoli } & \multicolumn{2}{|c|}{ Cabbage } & \multicolumn{2}{|c|}{ Broccoli } \\
\hline & 14 days $^{\mathrm{z}}$ & 42 days & 14 days $^{z}$ & 42 days & 14 days & 42 days $^{\mathrm{Z}}$ & 14 days & 42 days $^{z}$ \\
\hline Healthy & $98.7 \mathrm{a}$ & $95.0 \mathrm{a}$ & $86.3 \mathrm{ab}$ & $85.0 \mathrm{a}$ & $95.0 \mathrm{a}$ & $95.0 \mathrm{a}$ & $97.5 \mathrm{a}$ & $91.3 \mathrm{a}$ \\
\hline Superficial stem necrosis & $87.5 \mathrm{a}$ & $80.0 \mathrm{a}$ & $91.3 \mathrm{a}$ & $81.3 \mathrm{a}$ & $98.7 \mathrm{a}$ & $85.0 \mathrm{a}$ & $100.0 \mathrm{a}$ & $98.7 \mathrm{a}$ \\
\hline Stem partially girdled & $57.6 \mathrm{~b}$ & $51.1 \mathrm{~b}$ & $85.0 \mathrm{a}$ & $55.0 \mathrm{~b} *$ & 88.9 a & $79.4 \mathrm{a}$ & $96.0 \mathrm{a}$ & $84.2 \mathrm{ab}$ \\
\hline Stem girdled & $61.2 \mathrm{~b}$ & $33.1 \mathrm{c} *$ & $92.1 \mathrm{a}$ & $14.8 \mathrm{c} *$ & $81.6 \mathrm{a}$ & $33.6 \mathrm{~b} *$ & $89.8 \mathrm{a}$ & $74.1 \mathrm{~b}$ * \\
\hline Plant stunted & $7.2 \mathrm{c}$ & $0.0 \mathrm{~d}$ & $64.6 \mathrm{~b}$ & $0.3 \mathrm{c} *$ & $56.8 \mathrm{~b}$ & $19.4 \mathrm{~b} *$ & $55.0 \mathrm{~b}$ & $35.0 \mathrm{c} *$ \\
\hline
\end{tabular}

${ }^{x}$ Sum of symptomless and symptomatic plants, based on visual assessment of aboveground portions. Means within the same column with the same letter do not differ according to least-squares means $t$ tests, $P \leq 0.05$; $=$ difference between percentage survival at 14 and 42 days after transplanting is significantly greater than $0, t$ test, $P \leq 0.05$.

y Immediately before transplanting, seedlings were separated into wirestem severity classes based on symptoms on stems.

${ }^{\mathrm{z}}$ Crop-treatment interaction, $F$ significant at $P \leq 0.05$. 
planting. In a previous study on wirestem of $B$. oleracea crops, the percentage of symptomless plants also was negatively correlated with wirestem severity ratings (9).

The greatest impact of wirestem on transplants was on the percentage of plants that produced marketable-sized heads. Wirestem had a greater impact on percentage of plants producing marketable heads in the spring than in the fall, particularly for broccoli cv. Packman and for transplants of both broccoli and cabbage with partially girdled stems. Nevertheless, wirestem infection of transplants reduced yields of both crops in both seasons compared with healthy transplants. Moreover, both crops responded very similarly to the different severity levels of wirestem imposed. Yield measured as percentage or number of marketable heads decreased consistently with increasing wirestem severity. For heading $B$. oleracea crops, such as cabbage, broccoli, and cauliflower, one plant produces one head. Therefore, diseases such as wirestem that reduce plant survival and the total number of plants per hectare directly reduce yields.

Averaged over two on-farm trials in New York, Gratz (5) found that cabbage transplants "slightly" and "severely" affected with wirestem produced 12 and $36 \%$ fewer heads, respectively, than healthy transplants. Yield losses with cabbage (calculated from percent plants heading in Table 2) in this study were higher than those reported by Gratz: 48 and $20 \%$ in spring and fall, respectively, for transplants with partially girdled stems; $64 \%$ in both seasons for transplants with girdled stems; and 100 and $83 \%$ in spring and fall, respectively, for stunted transplants. Symp-

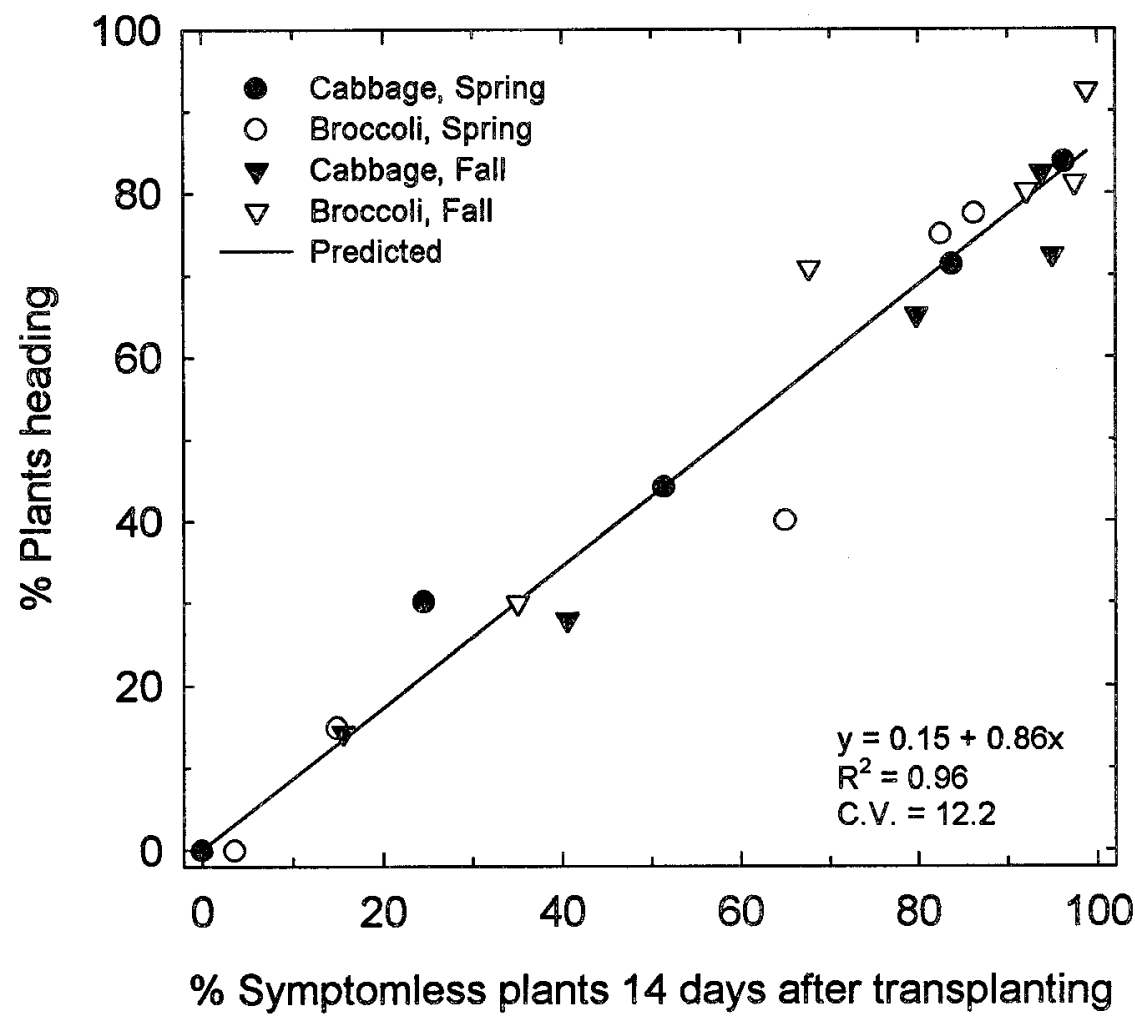

Fig. 2. Regression of percentage of cabbage and broccoli plants producing marketable-sized heads on the percentage of plants without symptoms of wirestem 14 days after transplanting in spring and fall. Each data point is the mean of four replications.

Table 3. Correlation of criteria used to evaluate the effects of wirestem severity of transplants on survival and yield of cabbage and broccoli plants in spring and fall experiments ${ }^{\mathrm{z}}$

\begin{tabular}{lcccc}
\hline & \multicolumn{4}{c}{ Plants } \\
\cline { 2 - 5 } Plants & $\begin{array}{c}\text { Symptomless, } \\
\text { 14 days (\%) }\end{array}$ & $\begin{array}{c}\text { Surviving, } \\
\mathbf{1 4} \text { days (\%) }\end{array}$ & $\begin{array}{c}\text { Surviving, } \\
\mathbf{4 2} \text { days (\%) }\end{array}$ & $\begin{array}{c}\text { Heading } \\
(\%)\end{array}$ \\
\hline Symptomless, 14 days (\%) & $\ldots$ & 0.66 & 0.97 & 0.96 \\
Surviving, 14 days (\%) & 0.87 & $\ldots$ & 0.64 & 0.64 \\
Surviving, 42 days (\%) & 0.94 & 0.83 & $\ldots$ & 0.97 \\
Heading (\%) & 0.89 & 0.76 & 0.95 & $\ldots$ \\
\hline
\end{tabular}

${ }^{z}$ Pearson's correlation coefficient for spring (top of diagonal) and fall (bottom of diagonal). There were 40 observations ( 20 for broccoli and 20 for cabbage), one per experimental unit, in each correlation. All correlations were significant at $P=0.0001$. toms of "slight" and "severe" wirestem were not described, but Gratz (5) indicated that growers normally set slightly diseased plants because they believed the plants had recovered, and discarded severely diseased ones. In another section of his bulletin, Gratz described the initial stage of wirestem as a watersoaked lesion at the soil line, from which most plants "recover[ed] partially", and a later stage after the cortex had decayed when plants were stunted with "tough, woody, wire-like stem[s]." We did not observe watersoaked lesions on transplants in this or previous studies $(8,9)$. The later stage of wirestem that Gratz described corresponded to our severity classes in which stems were girdled and plants may be noticeably stunted. It is possible that the fieldgrown transplants Gratz observed were more likely to be stunted than our transplants, which were inoculated in the greenhouse. The superficial stem necrosis observed on some inoculated transplants in this and other studies (8-10) had no effect on symptoms, survival, or yield.

Differences in the number of days required to produce a marketable-sized head depended on the season and the crop. In the spring, cabbage transplants with partially girdled stems matured more quickly than healthy plants. However, Gratz (5) observed a delay in maturity of cabbage grown from slightly diseased transplants in 1 of 2 years. Net returns on cabbage were estimated to be greatest for South Carolina producers in April, but would be lower if harvests were delayed until May, when cabbage harvest begins in North Carolina (16). In the fall, diseased broccoli plants produced marketable heads more slowly than healthy plants. Historically, broccoli prices have risen gradually in the fall (16). Therefore, an increase in the number of days to produce a marketable head because of wirestem may not result in a lower value for fall-grown broccoli. However, with delayed maturity, harvesting would have to be carried out over a longer period of time, increasing labor costs.

Traditionally, cabbage transplants have been produced in the field and may be infected with $R$. solani when they are shipped to growers or used on-farm (5). This has been a particular problem for cabbage growers in the southern United States in the fall, when fieldgrown transplants are produced in late summer when temperatures are favorable for growth of $R$. solani AG 4 and development of wirestem $(7,9,17)$. R. solani AG 4 has been recovered from Styrofoam planting trays used in greenhouses (6), so greenhouse-grown transplants also could be infected. Gratz (5) reported that, in the early stages of wirestem, before the cortex is destroyed, some plants recover. We also have observed that infected plants occasionally appear to recover and move from the diseased to the healthy category, based on 
appearance of aboveground symptoms (9 and unpublished). Based on these observations, it appears likely that, if enough healthy transplants were not available for fall planting, growers could use partially girdled transplants. This approach should allow a grower to produce a crop with minimal yield loss with the cultivars used in this study, and possibly others.

\section{ACKNOWLEDGMENTS}

We thank E. Gomperts, V. DuBose, and A. Rollins for technical assistance; L. Grimes, Department of Experimental Statistics, Clemson University, Clemson, SC, for statistical advice; and M. Cubeta and D. Sumner for reviewing this manuscript.

\section{LITERATURE CITED}

1. Baird, R. E. 1996. First report of Rhizoctonia solani AG-4 on canola in Georgia. Plant Dis. 80:104.

2. Butler, E. E. 1980. A method for long-time culture storage of Rhizoctonia solani. Phytopathology 70:820-821.

3. Campbell, C. L. 1986. Interpretation and uses of disease progress curves for root diseases. Pages 38-54 in: Plant Disease Epidemiology,
Vol. 1. Population Dynamics and Management. K. J. Leonard and W. E. Fry, eds. Macmillan Publishing Co., New York.

4. D'Ercole, N. 1974. Prove di suscettibilità varietale del cavolfiore all'infezione di Rhizoctonia solani Kühn in serra. Inf. Fitopatol. 6:11-12.

5. Gratz, L. O. 1925. Wire stem of cabbage. N. Y. State Agric. Exp. Stn. Mem. 85.

6. Gutierrez, W. A., Shew, H. D., and Melton, T. A. 1997. Sources of inoculum and management for Rhizoctonia solani damping-off on tobacco transplants under greenhouse conditions. Plant Dis. 81:604-606.

7. Kaminski, D. A., and Verma, P. R. 1985. Cultural characteristics, virulence and in vitro temperature effect on mycelial growth of Rhizoctonia isolates from rapeseed. Can. J. Plant Pathol. 7:256-261.

8. Keinath, A. P. 1995. Relationships between inoculum density of Rhizoctonia solani, wirestem incidence and severity, and growth of cabbage. Phytopathology 85:1487-1492.

9. Keinath, A. P., and Farnham, M. W. 1997. Differential cultivars and criteria for evaluating resistance to Rhizoctonia solani in seedling Brassica oleracea. Plant Dis. 81:946-952.

10. Rollins, P. A., Keinath, A. P., and Farnham, M. W. 1999. Effect of inoculum type and anastomosis group of Rhizoctonia solani caus- ing wirestem of cabbage seedlings in a controlled environment. Can. J. Plant Pathol. 21:119-124.

11. Ross, R. E., Keinath A. P., and Cubeta, M. A 1998. Biological control of wirestem on cab bage using binucleate Rhizoctonia spp. Crop Prot. 17:99-104.

12. Smith, J. P., and Keinath, A. P. 1995. Effects of wounding, transplant type, and planting depth on the incidence of wirestem, 1993. Biol. Cult. Tests 10:131.

13. Steel, R. G. D., and Torrie, J. H. 1980. Principles and Procedures of Statistics, 2nd ed. McGraw-Hill Book Co., New York.

14. Sumner, D. R. 1974. Ecology and control of seedling diseases of crucifers. Phytopathology 64:692-697.

15. van Bruggen, A. H. C., and Arneson, P. A. 1985. A quantifiable type of inoculum of Rhizoctonia solani. Plant Dis. 69:966-969.

16. Venturella, J. G., Rathwell, P. J., Bauer, L. L., and Caines, R. 1988. Potential market windows for selected vegetable crops in South Carolina. S. C. Agric. Exp. Stn. Bull. 663.

17. Yitbarek, S. M., Verma, P. R., Gugel, R. K. and Morrall, R. A. A. 1988. Effect of soil temperature and inoculum density on pre-emergence damping-off of canola caused by Rhizoctonia solani. Can. J. Plant Pathol. 10:93-98. 